IRA-International Journal of Education \& Multidisciplinary Studies

ISSN 2455-2526; Vol.05, Issue 01 (2016)

Pg. no. 8-15

Institute of Research Advances

http://research-advances.org/index.php/IJEMS

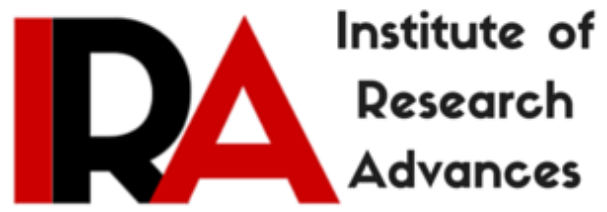

\title{
Emotional Intelligence Dimensions, Job Satisfaction and Primary School Teachers
}

\author{
Arun Kumar \\ Associate Professor, Department of Education, \\ Lucknow University, Lucknow (UP), India.
}

Type of Review: Peer Reviewed.

DOI: http://dx.doi.org/10.21013/jems.v5.n1.p2

\section{How to cite this paper:}

Kumar, A. (2016). Emotional Intelligence Dimensions, Job Satisfaction and Primary School Teachers. IRA International Journal of Education and Multidisciplinary Studies (ISSN 2455-2526), 5(1), 8-15. doi:http://dx.doi.org/10.21013/jems.v5.n1.p2

(C) Institute of Research Advances

\section{(cc) EY-NC}

This work is licensed under a Creative Commons Attribution-Non Commercial 4.0 International License subject to proper citation to the publication source of the work.

Disclaimer: The scholarly papers as reviewed and published by the Institute of Research Advances (IRA) are the views and opinions of their respective authors and are not the views or opinions of the IRA. The IRA disclaims of any harm or loss caused due to the published content to any party. 


\begin{abstract}
In this study, the researcher has tried to identify the relationship of five dimensions of emotional intelligence (Self-Awareness, Managing Emotions, Emotional Maturity, Empathy and Social competency \& social skills) with job-satisfaction. 400 primary school teachers were randomly selected from 150 primary schools of district Meerut. Self prepared Emotional Intelligence Scale (EIS) and Teachers' Job Satisfaction Scale' (TJSS) developed by Dr. J.P. Srivastava and Dr. S.P. Gupta was used. The data was analyzed with the help of SPSS-17 programme. The results of the study indicate that Emotional Intelligence is important have significant positive relationship with job satisfaction. Among all the five dimensions (self-awareness, managing emotions, maturity, empathy and social competency \& social skills) only managing emotions and maturity play major role in prediction of job satisfaction than the self awareness, empathy and social competency \& social skills, it means that emotional intelligence is good predictor of job satisfaction for primary school teachers.
\end{abstract}

Key words: Emotional intelligence dimensions, Job-satisfaction, Primary school teachers

\title{
INTRODUCTION
}

Now a day, teaching profession has become extremely challenging. In this age of computer and internet, information is just one click away from the students. This situation forces teachers into a very hectic and busy schedule. Due to which teachers are feeling stressed out, unhappy and dissatisfied. Besides teachings, primary teachers are forced to undertake many tasks which are not intended for them. Students' performance is usually related to teachers' ability to teach and function effectively. Intellectual intelligence (IQ) does not guarantee well being. In fact without Emotional intelligence (EI), a person can have the best training, an analytical mind and endless supply of ideas but will not make a great leader (Goleman, 2001).

Job satisfaction refers to a collection of attitudes, which workers have about their jobs. Berry (1997) defined "Job satisfaction as an individual's reaction to job experience". Job satisfaction describes how content an individual is with his or her job. There are a variety of factors that can influence a person's level of job satisfaction; some of these factors include the level of pay and benefits, the perceived fairness of the promotion system within a company, the quality of the working condition, leadership and social relationships and the job itself (the variety of tasks involved, the interest and challenge the job generates and the clarity of the job description requirement). The happier people are with their job, the more satisfied they are said to be. Various steps are taken by organizations to improve and enhance job satisfaction; these include job rotation, job enlargement and job enrichment. Other factors that influence job satisfaction include the management style and culture, employee involvement and autonomous work groups. Numerous authors have theorized that emotional intelligence contributes to people's capacity to work effectively in teams and manage work stress. (Caruso and Salovey, 2004).

Job satisfaction is a positive attitude, and individual has toward his job (Furnham, 1997; Mitchell and Kalb, 1982; Churchill et al., 1974). Working environment (Moriarty et al., 2001) and headmaster relationships with teachers (Menon and Christou, 2002) are significant sources of job satisfaction for teachers. Other factors that are just important contributors are relations with colleagues and students, opportunities to participate in decision making work condition, school culture, responsibility, communication, feedback from others and the nature of the work itself (Scott and Dinham, 2003; Chaplin, 1995). Looking at all the factors mentioned, it would seem that all the dimensions of EI would fit in very nicely with some of those factors. These days, researchers list numerous factors as affecting the job satisfaction of employees including: payment, the nature of the work, promotion, leadership and supervision, relations with coworkers, job safety, organizational structure, physical conditions of the job, personality factors, personal characteristics, and equality. Emotional intelligence can as well influence job 
satisfaction, since the happier people are with their job the more satisfied they are said to be which entails the expression of emotion. It is a fact that it takes more than traditional cognitive intelligence to be successful at work. It also takes emotional intelligence; the ability to restrain negative feelings such as anger and self-doubt, and rather focus on positive ones such as confidence to be successful at work.

Bar-On (1997) in his study found a positive relationship between a combination of the dimensions of EI, interpersonal relationship, intrapersonal relationship, self-adaptability, stress management and overall feeling with job satisfaction. A negative relationship between EI and burnout and positive relationship between EI and job satisfaction was found by Platsidou (2010). Teachers with high EI is likely to experience grater job satisfaction (Wong et al., 2010). EI was significantly and positively related to job satisfaction and organizational commitment (Guleryuz et al., 2008). Kafetsios and Zampetakis (2008) indicated that positive and negative affect and research substantially mediate the relationship between EI and job satisfaction with positive effect exerting a stronger influence.

Umadevi M.R. (2009) in her study "Relationship between emotional intelligence, achievement motivation and academic achievement", she examined the relationship between emotional intelligence, achievement motivation and academic achievement of primary school student teachers. Emotional intelligence scale and achievement motivation test was administered on 200 D.Ed. students, and the data obtained was subjected to descriptive, correlation and differential analysis. The objectives of the study were: to find out the relationship between emotional intelligence, and academic achievement of student teachers, to find out the relationship between achievement motivation and academic achievement of student teachers, and to compare the emotional intelligence and achievement motivation of student teachers with respect to sex and arts and science groups. It was found that there is a positive relationship between emotional intelligence and academic achievement of primary school student teachers, there is a positive relationship between achievement motivation and academic achievement of primary school student teachers, male and female, student teachers, arts and science student teachers do not differ in emotional intelligence, and male and female student teachers, arts and science student teachers do not differ in achievement motivation.

Afolabi et al. (2010) in their study examines the influence of emotional intelligence and gender on job performance and job satisfaction among Nigeria Police Officers. It employs a 2x2 factorial design as well as multiple regressions with emotional intelligence and gender as the independent variables. One hundred and nineteen police officers were randomly selected from Esan Area Command. The results show that Police Officers who are of high emotional intelligence are more satisfied and perform better than Police Officers who are of low emotional intelligence. Also, respondents who have male or female roles with high emotional intelligence perform better and more satisfied with their job than respondents who have male or female roles with low emotional intelligence.

In a study on 215 physical education teachers Mousavi, S.H et al. (2012) found that there is a significant positive relationship between emotional intelligence and job satisfaction $(\mathrm{r}=0.349)$ and between the components of social skills, empathy, and motivation and job satisfaction at level. Further, the results of stepwise regression showed that among the five components of emotional intelligence, social skills (0.442), empathy (0.302), and motivation (0.235) were predictors of teacher's job satisfaction. The calculated Fisher's z revealed that the difference between the correlation between the teachers with diploma and those with MSc is significant at 0.05 level. It seems that job satisfaction of teachers can be increased by training and improving their emotional intelligence along with providing facilities and satisfying their needs.

Di Fabio et al. (2012), on Italian university students looked at the relationship between career indecision and personality traits, career decision-making self-efficacy, perceived social support and selfreported emotional intelligence according to the Bar-On model (1997). The results showed that emotional 
intelligence explained a percentage of the incremental variance with respect to both personality traits and career decision-making self-efficacy and perceived social support in relation to both career indecision and indecisiveness. While career indecision was better explained by emotional intelligence, indecisiveness was better explained by personality. The study could thus investigate in depth the two constructs and highlight their convergences as well as their divergences.

In a study Syed Sofian Syed Salim et al., (2012) found a significant positive relationship between EI and job satisfaction and no effect of gender on the relationship between the two variables. On the contrary by Donaldson-Feilder and Bond (2004) on 290 workers in the UK suggests that neither EI nor acceptance is associated with job satisfaction. Many findings suggest that emotionally intelligent persons are better performer than their counterpart but most of these associations are based on self-report measures of emotional intelligence.

Kumar, A (2016), in a study of relationship between emotional intelligence and job satisfaction of secondary school teachers concluded that Emotional Intelligence and Job Satisfaction are significantly and positively correlated with each other. The gender plays an important role in emotional intelligence. female have significantly higher level of emotional intelligence in comparison to male and the secondary school teachers both male and female who lived in urban areas have significantly higher level of emotional intelligence in comparison to teachers who worked in rural areas.

\section{RESEARCH QUESTIONS:}

The following questions have been formulated for this study.

1. Is there any relationship between emotional intelligence and job satisfaction?

2. To which extent dimensions of emotional intelligence affect job satisfaction among primary school teachers?

To know the answer of the above questions following objectives for this study have been formulated.

\section{OBJECTIVES:-}

1. To study the relationship between emotional intelligence and job satisfaction.

2. To study the influence of emotional dimensions on job satisfaction of primary school teachers.

\section{HYPOTHESES:-}

The following hypotheses were formulated -

1. Ho1. There is no significant correlation between emotional intelligence and job satisfaction of primary school teachers.

2. Ho2. There is no significant contribution of five dimensions of Emotional Intelligence on job satisfaction.

\section{METHODOLOGY:-}

The normative survey method has been used in this study, 400 primary school teachers were randomly selected from 150 primary schools of district Meerut. To collect the data, Emotional Intelligence Scale (EIS) was developed by the researcher. The EIS include five dimensions of EI vizSelf-Awareness, Managing Emotions, Emotional Maturity, Empathy and Social competency \& social skills. Each field contains 16 items. Finally, total 80 items were included in the Scale. The test -retest reliability and validity of test was $0.89 \& 0.626$ respectively. To measure the job satisfaction of the teachers Teachers' Job Satisfaction Scale' (TJSS) developed by Dr. J.P. Srivastava and Dr. S.P. Gupta was used. The data was analyzed with the help of SPSS-17 programme. 


\section{ANALYSIS, RESULTS AND DISCUSSION}

The analysis of data was done hypothesis wise through SPSS-17 for the formulation of results and interpretation with discussion.

\section{Analysis-1:}

To measure the objective 1, Hypothesis Ho1 "There is no significant correlation between emotional intelligence and job satisfaction of primary school teachers", has been analysed. The coefficient of correlation has been calculated through Pearson correlation between Emotional intelligence and Job- Satisfaction. The calculated value is shown below in table-1.

Table -1

Coefficient of correction between Emotional Intelligence and Job Satisfaction

\begin{tabular}{|l|l|c|}
\hline \multicolumn{2}{|c|}{} & Job Satisfaction \\
\hline Emotional Intelligence & Pearson Correlation & $0.573^{* *}$ \\
\cline { 2 - 3 } & Sig. level & .000 \\
\hline
\end{tabular}

**. Correlation is significant at the 0.01 level (2-tailed).

RESULT-1: The obtained coefficient of correction value ' $r$ ' is 0.573 , which is significant at 0.01 level of significance. It means that there is a moderately positive and significant correlation between emotional intelligence and job satisfaction of primary school teachers. So, Hypothesis Hol gets rejected.

DISCUSSION-1: The result of the study shows that there is a positive and significant relationship between Emotional Intelligence and job satisfaction among primary school teachers. This mean that higher the level of Emotional Intelligence, the higher the job satisfaction and vice versa. This finding support previous studies by Bar-On (1997), Guleryuz et al. (2008), Kafetsios and Zampetakis (2008), Platsidou (2010) and Syed et al. (2012). Emotional Intelligence is said to be able to affect one's ability to succeed in coping with environmental demand and pressure, clearly an important set of behaviors to harness under stressful work condition (Bar-On, 1997). It is clear from this study that the primary school teachers experience job satisfaction despite the challenges and demands of their jobs. According to Goleman (1998a, 1998b), individuals who have high EI are able to know and feel their own and others' emotions. These individuals are able to make better, accurate and rational decisions, produce a more realistic assessment and have high confidence in themselves. The abilities are no doubt very important in the teaching profession whereby teachers are constantly expected to make decisions based on their understanding of their students' behaviors, emotions and cognitions. In addition the ability to understand and appreciate the emotions of others in an organization is also an important aspect of EI in order to create harmony within an organization. In this context, one could say that this ability would help teachers in their ability to create harmony within school.

\section{ANALYSIS-2:}

The objective 2 for the hypothesis Ho2 "There is no significant contribution of five dimensions of Emotional Intelligence on job satisfaction" have been verified through multiple regression analyses to ascertain the relationship and contribution of the five dimensions of Emotional Intelligence viz self awareness, emotional management, emotional maturity, empathy and social competency \& social skills. The result of the analysis is shown in Table -2 . 
Table -2

A summary of Multiple Regression Analysis of five Dimensions of Emotional Intelligence and job satisfaction

\begin{tabular}{|l|c|c|c|c|c|c|c|}
\hline \multirow{2}{*}{$\begin{array}{l}\text { Emotional } \\
\text { Intelligence }\end{array}$} & \multicolumn{2}{|c|}{ Job-satisfaction } & & \multirow{2}{*}{} & \multicolumn{2}{|c|}{ Job-satisfaction } \\
\cline { 2 - 4 } \cline { 6 - 8 } & $\mathrm{B}$ & $\mathrm{Beta}$ & $\mathrm{F}$ & $\mathrm{t}$ & $\mathrm{Sig}$. & $\mathrm{R}$ & $\mathrm{R}^{2}$ \\
\hline Dimensions of EI & - & - & 30.40 & - & 0.000 & $0.584^{\mathrm{a}}$ & 0.341 \\
\hline Self Awareness & 0.173 & 0.037 & $\mathrm{df}=5$, & 0.590 & 0.556 & & \\
\hline Managing Emotions & 1.239 & 0.315 & 294 & 4.010 & 0.000 & & \\
\hline Emotional Maturity & 0.778 & 0.174 & & 3.144 & 0.002 & & \\
\hline Empathy & 0.385 & 0.109 & & 1.399 & 0.163 & & \\
\hline $\begin{array}{l}\text { Social Competency } \\
\text { and Social Skills }\end{array}$ & 0.493 & 0.103 & & 1.660 & 0.098 & & \\
\hline
\end{tabular}

RESULT-2: The results showed that the value of correlation coefficient of the five dimensions of Emotional Intelligence on job satisfaction $(R=0.584)$ is average positive and significant. These finding showed that teachers who were generally at the high and average level of Emotional Intelligence were normally satisfied with their job. The regression analysis of the five dimensions of Emotional Intelligence with job satisfaction indicates that the derived regression equation is significant $(\mathrm{F}=30.40$; $\mathrm{p}<0.01)$. Value of beta weight for each dimension showed that emotional management $(\mathrm{t}=4.01, \mathrm{p}<0.01)$ and emotional maturity $(\mathrm{t}=3.14, \mathrm{p}<0.01)$ has a significant predictive power for job satisfaction while the other three dimensions, on the contrary, showed insignificant predictive power. The joint influence of all the five dimensions of Emotional Intelligence is represented by $\mathrm{R}^{2}(0.341)$. which means that all dimensions of emotional intelligence have combined affect $34 \%$ on job-satisfaction. Table -2 , shows that emotional management contributed $32 \%$, emotional maturity contributed $17 \%$ of total beta weight. It is clear that only emotional management and maturity have power of prediction of job satisfaction of primary school teachers.

\section{DISCUSSION-2}

The Results also showed that the five components viz self-awareness, managing emotions, maturity, empathy and social competency \& social skills are positively correlated with the job satisfaction. These results were supported by the (Goleman, 1998a) by stating that the ability to adapt to the mood of other individuals or to empathize is also one of the characteristics of a person with high Emotional Intelligence. Adaptability and empathy will make it easier for a teacher to interact well and effectively with both teachers and students. This indicates that individuals with high Emotional Intelligence also have good social skills. They can easily adapt to the working environment and find satisfaction in their work. The individual with high Emotional Intelligence will create a good, harmonious and conducive environment which will intern give them satisfaction in careers that they pursue (Cherniss, 2001).

\section{CONCLUSION}

The findings of the present study indicate that Emotional Intelligence is important in-terms of its relationship with job satisfaction. It also influences human behavior as a whole. So not only in the field of education but also in all field of life, Emotional Intelligence play a vital role. Though there are a lot of other factors other than self-awareness, managing emotions, maturity, empathy and social competency \& social skills, which affect job satisfaction. But role of these factors cannot be neglected. The ability to manage their own emotions as well as other emotions and high level of emotional maturity significantly predicts the job satisfaction of a teacher. A teacher, besides teaching work, also have to deal with daily 
pressure and challenges, including above mentioned quality of emotional intelligence teachers' social competency and social skills must be considered in the selection of the State and Centre school selection boards..

\section{REFERENCES}

1. Afolabi, O.A; Awosola, R.K. and Omole, S.O. (2010): Influence of EI and gender on job performance and job satisfaction among Nigerian policeman. Current research journal of social sciences, 2(3): 147-154.

2. Bar-On, R. (1997): The emotional quotient inventory (EQ-i): Technical manual. Multi health systems, Toronto, Canada.

3. Berry, L.M. (1997): Psychology at Work: San Francisco: McGraw Hill Companies.

4. Caruso, D.R. and P. Salovey, (2004): The emotionally intelligent manager: How to develop and use the four key emotional skills of leadership. San Francisco, CA: Jossey-Bass.

5. Chaplin, R.P. (1995): Stress and job satisfaction: a study of English primary school teachers. Educ. Psychol., 15: 473-489.

6. Cherniss, C. (2001): EI and organizational effectiveness. In: The Emotionally intelligent workplace, Cherniss, C. and D. Goleman, (Eds.). Jossey-Bass, California, pp: 3-12.

7. Churchill, G.A., N.M. Ford and O.C. Walker, (1974): Measuring job satisfaction of industrial saleman. J. Market Research, 11: 254-260.

8. Di Fabio, A (2012). Emotional Intelligence - New Perspectives and Applications. InTech, Shanghai, China.pp 59-66. ISBN: 978-953-307-838-0, http://cdn.intechopen.com/pdfs-wm/27239.pdf.

9. Donaldson -Feilder, E.J. and F.W. Bond (2004): The relative importance of psychological acceptance and emotional intelligence to workplace well-being. Br. J. Guidance Counseling, 32: 187-203.

10. Furnham, A., (1997): The psychology of behavior at work. Psychology Press, Hove, UK.

11. Goleman, D., (1998a): What makes a leader? Harvard Bus. Rev., 76: 93-102.

12. Goleman, D., (1998b): Working with EI. Bantam Books, New York.

13. Goleman, D. (2001): What makes a leader? In. Creative Management, Henry, J. (Ed.). Sage Publication, London.

14. Guleryuz, G., S. Guney, E.M. Aydin and O. Asan, (2008): The mediating effect of job satisfaction between emotional intelligence and organizational commitment of jurses: a questionnaire survey. Int. J. Nursing Stud., 45: 1625-1635.

15. Kafetsios, K. and L.A. Zampetakis (2008): Emotional intelligence and job satisfaction: Testing the mediatory role of positive and negative affects at work. Personality Individual Differences, 44: 712-722.

16. Kumar, A. (2016), Emotional Intelligence and School teachers, Parimal publications ISBN: 978-817110547-2, Delhi.

17. Menon, M.E. and C. Christou, (2002): Perceptions of future and current teachers on the organization of elementary school: A dissonance approach to the investigation of job satisfaction. Educ. Res., 44: 97-110.

18. Mitchell, T.R. and L.S. Kalb (1982): Effect of job experience on supervisor attribution for a subordinate's poor performance. Journal of Applied Psychology, 67: 181-188.

19. Mousavi, S.H., Yarmohammadi, S, Nosrat, A.B., and Tarasi, Z. (2012): The relationship between emotional intelligence and job satisfaction of physical education teachers. Annals of Biological research, 3(2): 780-788.

20. Platsidou, M. (2010): Trait emotional intelligence of Greek special education teachers in relation to burnout and job satisfaction. School Psychol. Int., 31: 60-76.

21. Scott, C and S. Dinham, (2003): The development of scales to measure teachers and school executive occupational satisfaction. J. Educ. Admin., 41: 74-86. 
22. Syed Sofian Syed Salim, Rohany Nasir, Mohammad Azia Shah Mohamed Arip and Muhammad Bazlan Mustafa (2012): The role of emotional intelligence and job satisfaction among school teachers. The Social Science, 7(1): 125-129.

23. Umadevi, M.R. (2009). A study of Relationship between emotional intelligence, achievement motivation and academic achievement, Edutracks. Vol. 8. No. 12, Nilkamal Publications, Hyderabad, p.31-35

24. Wong, C. S., P.M. Wong and K.L. Peng (2010): Effect of middle-level leader and teacher emotional intelligence on school teachers' job satisfaction: The case of Hong Kong. Educ. Manage. Admin. Leadersh, 38: 59-70. 